\title{
EVALUATION OF THE EFFICIENT LEVEL OF USEFUL AGRICULTURAL SOILS
}

\author{
Akif Valiyev', Natig Mirzayev ${ }^{2}$ \\ ${ }^{1}$ Ministry of Agriculture of the Republic of Azerbaijan, Agricultural Economics Research \\ Center; ${ }^{2}$ Lankaran State University
}

\begin{abstract}
The article describes overall useful agricultural soil in Azerbaijan, as well as the level use in crop production and animal husbandry, as well as the quality and evaluation of variety of crops in accordance with a system of 100 points under the land cadastre.

To determine the efficient level of useful agricultural soils, first of all, the main types and subtypes of soil and their cultivated area used in agricultural production were identified. Data was calculated on the overall soil fund of the republic, the agricultural region and its composition (structure), the level of use of each type and subtype of soil in agriculture, as well as in crop production and animal husbandry. Calculations show that the total utilization rate in agriculture varies between 0.52 and 0.98 .

To assess the quality of the type and subtype of soil used in agricultural production, to assess the quality of various plants, a system of 100 points was used, and it was proposed to combine the soil in 10 agricultural production groups instead of 5 There are ways to calculate the "Comparative soil value" (TMDӘ) for a specific territory to simplify and facilitate the practical use of materials from agricultural soil groups.

Using the data obtained from the survey, any farm manager can plan to obtain higher yields per unit area with minimal and less labor, and can also determine the need of plants for fertilizers depending on soil quality.

Key words: soil, agriculture, useful soil, quality of soil, productivity, evaluation.
\end{abstract}

\section{Introduction}

Despite its small territory, Azerbaijan has diverse and complex natural and economic conditions. In terms of agricultural suitability, Azerbaijan is one of the smallest countries in the world. This forces to be more careful and make the right decisions both in the use of soil resources as a natural, and in the organization of agricultural production.

Soil is the main production tool in agriculture, which is the basis of its economic development. The economic condition of agriculture depends on how much of its soil is used to be efficiently and effectively. The efficient use of soil resources, protection and improvement of their fertility have always been considered actual issues.

Conducting a quantitative and qualitative land inventory to ensure the efficient use of agricultural soil, determine the directions of agricultural production, study the quality of soil cover, find out how good (bad) or bad (less productive) is. It is important to determine the extent of soil use in agriculture. All this can be achieved through land cadastral work, which includes reliable, necessary and reasonable information about the natural quality of the soil, its economic and legal status.

It is known that in a concrete area, not only one but also several varieties of soil are found, and their quality is also different. This makes it difficult to use cadastral data for this soil in agriculture, and to overcome this difficulty, the soil is grouped according to quality indicators. This grouping is called agro-production grouping of soil. In Azerbaijan, the soils are grouped into 5 agro-production groups according to a 100-point system, and the difference between the soils of each group is equal to 20 points. Research shows that the difference in this limit does not allow us to correctly assess productivity depending on the quality of the soil. Taking this into account, we considered it appropriate to carry out improvements in the agro-production grouping of soil.

Therefore, the main purpose of the article was to determine the level of use of soils suitable for agriculture, to assess the quality of the soils in accordance with the demand of different plants and to improve the grouping in terms of agro-production.

\section{Methodology of research and materials}

At first glance, determining the extent to which useful agricultural soil can be used is simple and easy, but it is a very complicated process. Usually, researchers, especially economists, pay more attention to the soil use and to what extent the culture is used under the agricultural crop, that is, the structure of the soil fund. Of course, knowledge of the structure of the soil fund is one of the key, but it is 
important to remember that not every plant is able to grow and produce high yields in any soil. There are certain soils that include the qualitative characteristics of each plant, and it is important to consider this factor when using these soils. Because the qualitative and economic valuation of soil, as well as the calculation of the standard price (monetary value) of soil should be determined based on the qualitative and productive characteristics of each land.

For 2019, according to the State Committee on Property Issues of the Republic of Azerbaijan, 4779.5 thousand hectares with a total area of 8655.5 thousand hectares are useful for agriculture. Of these, 1895.0 thousand ha $(21.9 \%)$ are used for planting various crops, 186.9 thousand ha $(2.1 \%)$ - for perennial cultivation, 2317.8 thousand ha $(26.8 \%)$ - for pasture, and the rest - for other crops, 1040.4 thousand ha $(12.0 \%)$ of the rest of the republic are forest fund soils, 984.8 thousand ha $(11.4 \%)$ of other categories, 1850.8 thousand ha (21.4\%) of other purposes (Table 1$)$.

Composition of the General Soil Fund of the Republic of Azerbaijan (data of 2019)

\begin{tabular}{|l|c|c|}
\hline \multicolumn{1}{|c|}{ Places of use of soils } & \multicolumn{2}{c|}{ General Soil Fund } \\
\cline { 2 - 3 } & $\begin{array}{c}\text { area, thousand } \\
\text { ha }\end{array}$ & $\mathbf{\%}$ \\
\hline Total area of the Republic & 8655.5 & 100.0 \\
\hline Total of suitable areas for agriculture, including: & 4779.5 & 55.2 \\
\hline sown area & 1895.0 & 21.9 \\
\hline perennial plantations & 186.9 & 2.1 \\
\hline pasture areas & 2317.8 & 26.8 \\
\hline other agro plants & 379.8 & 4.4 \\
\hline Forest Fund soils & 1040.4 & 12.0 \\
\hline Soils belonging to other categories & 984.8 & 11.4 \\
\hline Different fixing of soils & 1850.8 & 21.4 \\
\hline
\end{tabular}

To find out the degree of soil use, it is necessary to determine the main types and subtypes of the soil that are considered useful for agriculture, both their total and actual area used for crops. For this purpose, you are able to use the available data for a specific area, statistics, research materials and funds.

Soil scientists of the republic found that the diversity of natural conditions and the influence of the ancient agricultural culture led to the formation of a complex and diverse soil cover in Azerbaijan. They are most widely used in agricultural production: mountain gray-brown (mountain chestnut)(371.4 thousand ha), brown (262.0 thousand ha), meadow-brown (332.2 thousand ha), dag-gara (mountain black)-(75.8 thousand ha), podzoll yellow (28.2 thousand ha), podzoll-yellow clayey (57.4 thousand ha), brown-grey (chestnut) -1028.7 thousand ha), gray (166.5 thousand ha), gray (915.5 thousand ha), gray-meadow (1311.2 thousand ha), meadow (458.4 thousand ha), sub-alluvial meadow (647.3 thousand ha) and etc., soil types and subtypes (Babayev M., Hasanov V.,2001, Mamedov Q., 2000, Valiyev A., 2011).

It is important to calculate coefficient of soil use $\left(\mathrm{T}_{2}\right)$ based on the comments of N.N. Rozov in order to determine the degree of agricultural soil use (Розов H. 1962). Thus, it is possible to determine the degree of soil use for any crop with concrete numerous. It is proposed to calculate the soil use coefficient according to the following formula (1):

$$
\mathrm{T}_{ə}=\mathrm{S}_{\mathrm{i}}: \mathrm{S}_{\mathrm{ü}}(1)
$$

where: Tə - coefficient of soil use; $\mathrm{Si}$ - actually used soil area; Sü - total area of that soil.

After determining the degree of use of soils suitable for agriculture, their quality scores were calculated on the basis of bonitirovka. In accordance with the quality score, the soils were combined in agro-production groups. To simplify and facilitate the practical use of materials of agricultural soil groups, you are able to calculate the "Comparative soil value" (TMDӘ) in a particular area. To do this, you can use the following formula (2): 


$$
\mathrm{Tmd} \mathrm{a}=\mathrm{Tb}: \mathrm{Tob},(2)
$$

where: Tmdə - coefficient of the comparative value of soils,

$\mathrm{Tb}$ bonitet (quality) of the soil,

Tob the average bonitet (quality) score of the soil area.

Using this formula, we are able to calculate any agro-production (comparative value coefficient of soils belonging to quality group).

It is necessary to calculate the comparative cost of soils of the III group of agricultural production, and in this group the index of bonitet of dark mountain-gray brown soils under crops is 78, typical mountain-gray-brown soils -73 , chestnut -80 , light chestnut soils - 77 , gray-meadow soils -75 and gray -71 . In this case, the average soil value estimate for the quality group was found $(78+73+80+$ $77+75+71: 6=76$ ). Then, using the proposed formula, we are able to calculate the relative cost of soil for each soil, or agro-production group, or any territorial unit. The comparative soil value belonging to the III group of agricultural production, as a result will be $1.03 ; 0.96 ; 1.05 ; 1.01 ; 0.99$; 0.93 . If the comparative value soils is equal $(\mathrm{TMD} \partial=1)$ or higher than one $(\mathrm{TMD} \oslash>1)$, then there is no need for additional resources to increase or improve the fertility of these soils or agro-industrial groups. Conversely, if the relative value of land is lower than unit $(\mathrm{TMD} \partial<1)$, then additional costs should be increased to improve land quality.

\section{Discussions and results}

Thus, using proposed procedure, the degree of useful soil in the country as a whole for agriculture, including crop production and animal husbandry, was determined (Rozov H., 1962). According to the calculations, the utilization of all soil in agriculture as a whole range between 0.52 and 0.98 . The coefficient use of mountain gray-brown (mountain-chestnut) soils in crop production 0.21 and 0.31 in animal husbandry. It also means that these soils are mainly used for animal husbandry, as they are mainly pastures. The reasons for the scarcity of these soils are different, but one of the main reasons is that they spread along the slopes and undergo intensive erosion. Nevertheless, there are extra opportunities for the use of these soils in agriculture.

The relatively used meadow brown (Tə - 0.61) and mountain black soils (Tə - 0.68) are among the best in soil in terms of fertility. Since they have a rich vegetation cover, the erosion process here is also relatively weak. Therefore, the use of these soils at a low level is regrettable.

The most commonly used soils in agriculture are gray ( podzoll-yellow ( $\mathrm{T}$ - -0.94$)$ and gray-meadow ( $\mathrm{T}$ - -0.90$)$ types and subtypes of soil (Valiyev A., 2011). This is also natural, since this group of soils is mainly used in the irrigated territories of the republic, in the lowlands and foothills and is widely used under the various crops. The yellow soil group is distributed over a small area in the foothill plains of the Lankaran economic region and is mainly used for tea, subtropical vegetation and partially for vegetable growing. Low soil and population density also contribute to the intensive use of these soils. Since they do not have a large area and are useful for use, it is advisable to use them only for the growth of tea and subtropical plants, since these plants are able to grow only on these soils.

Although meadows and meadow-wetland soils are widely used in agriculture, and at a very low level. Of these soils, Tə -0.68 in general agriculture, $0.13-0.15$ in crop production and $0.53-0.55$ in animal husbandry. Favorable conditions have been created here for the broad development of breeding, fodder and vegetable growing.

Thus, it was determined that the part of the main type and semi-sub-type soils spread in the territory of the Republic injured to agriculture is equal to 5610.9 thousand hectares, the coefficient of its use in agriculture is equal to 0.84 ( 4779.5 thousand ha). It was calculated that about 831,4 thousand hectares of these soils remained unused, and most of them (more than 60\%) are quality soils.

These soils can be defined, mapped and used in agricultural production in the order of their structure. In addition to agricultural soil throughout the country, exception forest fund soil can be directly involved in agricultural use, and some areas can be used directly in agriculture with appropriate measures (areas listed above with hectares). However, for this purpose, the cadastre and land management should be invented, mapped, and quantitative and qualitative records should be reviewed. Thus, using the proposed rule, it is possible to determine the degree of soil use in any district, farm or district. It should also be noted that the accuracy of determining accuracy is higher when determining soil use in small areas. 
After determining the extent of quantitative soil use as an integral part of the cadastre, it is necessary to assess its quality, that is, the level of agricultural production. These datum are very important not only for the efficient use of soil, but also for the construction of a profitable farming system, the determination and purchase of normative prices (value by money) of soil. Also, they are widely used in the implementation of other land-related deals, planning and forecasting of agricultural production, management and specialization of farms, as well as in the solution of many issues that ensure the development of agricultural production.

It is known that the quality and productivity of soil as a means of production is determined by its fertility. Soil fertility is formed as a result of a natural process and forms of its value. Various methods are used to determine how fertile one soil is from another. The method we use is called soil "assessment (bonitirovka)".

Soil quality assessment in Azerbaijan, i.e. "Bonitirovka", was carried out on the basis of the 100-point system proposed by F. Gavrilyuk (Гаврилюк Ф. 1974). However, in our study, we did not have the highest quality indicators in accordance with this method. In this case, it is possible to more accurately determine the actual quality of the soil, as well as the plant's need for soil. This is clearly seen by assessing the diversity of the main types and semi-arable land used in agriculture.

Thus, although the overall quality index of brown-grey (chestnut) soils used in agriculture was 72 , the demand for crops was 76 , vegetables were 86 , grapes were 88 , and 90 for fruits. Or gray soils have a total quality score of 66 , for grain 54, for cotton 76, for vegetables 72 , for fruits 66 and 64 for grapes. The overall quality index of podzoll yellow soils was 78 , for tea plants -89 points, vegetables - 80 points and grain - 73 points. Thus, such calculations (other types and subtypes of soils) can be made to determine which soil is most useful for the plant and which plant is most useful for other species. For example, gray soils are considered more useful for cotton and vegetable crops.

Thus, based on the valuation, you can determine how much the quality of the soil is different. It should be noted that due to geographical conditions in one area you can meet more than one species. This greatly complicates the use of the results of the land cadastre in agriculture. To overcome such problems, land classification by quality indicators is necessary.

Since soil is the main production facility in agriculture, this grouping is called the agro-industrial (soil) classification of soil. Agro-industrial classification of soils is a grouping of soils that have the same properties due to their genesis and agronomic quality.

Agro-industrial classification of soils solves many common problems of agricultural production: specialization of farms, the right choice of soil, determining which plant to grow, forecasting productivity, evaluating the production activity of farms and determining potential soil productivity. is of paramount importance.

In the 60-70s of the last century in Azerbaijan there were two types of soil: special and general agricultural production. In a special group - the main diagnostic indicators and qualitative characteristics of the soil (chemical and physical indicators, salinity, salty (salinity), erosion, etc.) are based on the general group - the need for specific agricultural plants in the soil. Subsequently, agroindustrial classification of land on the basis of accrued points was given more space. According to this 100-point system, soils were grouped into the following 5 agricultural production groups based on bonuses, each of which included 20 points:

I group - high quality soils (100-81 score);

II group - good quality soils (80-61 score);

III group - medium quality soils (60-41 score);

IV group - low quality soils (40-21 score);

$\mathrm{V}$ group - conditionally unsuitable soils (20-1 score).

We believe that each approach to the classification of agricultural soils has its advantages and disadvantages. Given the complexity and difficulty of the problem, these shortcomings should be naturally accepted. However, we must not forget that the main goal of a qualitative assessment of soils, as well as the agro-industrial group, is the efficient use of soil and its fertility, as well as an increase in agricultural production. If the quality of the soil (bonitet scores) or the agro-industrial grouping does not serve the purpose, it does not matter.

As you can see, the difference between the soil quality indicators of each agro-industrial group is 20. If we consider the soil as a natural product and not as the main production object, then the fact that the difference of 20 scores between agro-industrial groups and intra-group soils cannot be a real indicator of its quality and economic indicators. That's an example. For example, in the Barda region, Farida's business produces 50 centners of grain per hectare, and the soil quality indicator is 67 . This means that 
the price of each piece of soil will be 0.7 cents / ha. Then the price of one ton of soil quality is more than 8.0 EUR with current exchange rate, if we calculate the sale price of each centner of grain. If we assume that the quality of the soil in the same agro-production group is 20 score, then it is 161.5 EUR (8.0 EUR x 20 score $=161.5$ EUR), which does not fully reflect reality.

In our opinion, agricultural soil classification should be based on the nearest points obtained by the quality of toxic soil units and the needs of a particular plant. The genetic and production characteristics of soils with this classification, their relationship with the main agrotechnical and reclamation measures, the level of use of material and technical resources, such as fertility, economic indicators, labor costs, potential land productivity, etc., issues are also taken into account.

Based on the foregoing, it is more expedient to combine the republic's lands in the following 10 agroindustrial groups in accordance with the bonitet classes:

I group - the highest quality soils (100-91 score);

II group - high quality soils (90-81 score);

III group - the best quality soils (80-71 score);

IV group - good quality soils (70-61 score);

$\mathrm{V}$ group - medium quality (60-51 score);

VI group - relative medium quality soils (50-41 score);

VII group - low quality soils (40-31 score);

VIII group - the lowest quality soils (30-21 score);

IX group - conditionally unsuitable soils (20-11 score);

$\mathrm{X}$ group - Incomplete soils (areas) (10-1 score).

Since this group reflects reality, it is also a group of agri-food groups, in addition to being accessible from the point of view of maintaining and improving soil fertility, efficient use, productivity and organizing proper management and development of implementation measures of the farm, simultaneously also facilitates the practical application of materials and datas.

Using the "Comparative Value Coefficient of Soil" (TMDӘ), it is possible to calculate the coefficient of comparative value of soil in any territorial unit and determine the amount of funds needed to increase the productivity of soil in that territory, thereby preventing excess costs incurred in the farm.

Using this data, any farm manager is able to plan their production in such a way that higher productivity per unit area can be achieved with minimal cost and labor. For example, data on soil quality (fertility) is of great practical importance for the development and implementation of measures to reduce the cost and productivity of crops, the effective and proper use of fertilizers and the implementation of relevant agricultural measures. It is important to know how much and what plants need for fertilizers, as well as the size and quality of the soil so that they can be used correctly and in a timely manner. To determine the duration and speed of irrigation, it is necessary to obtain cadastral data on the water-physical and chemical characteristics of the soil.

\section{Conclusions and proposals}

Based on the research, it can be concluded that in order to increase the economic efficiency use of agricultural soil in the republic, it is necessary to conduct an accurate inventory of soil and its natural resources (agricultural areas).

It is established that agricultural soil is not fully utilized. Unused soil, land cadastre and land management should be identified and mapped on the spot and involved in agricultural production.

In order to correctly assess the quality and productivity of the soil, cadastral work should be carried out on the basis of new indicators and the use of modern methods.

Based on the study, we consider it expedient to combine agricultural soil in the republic into 10 agro production groups, and not into 5 agro production groups.

"Comparative soil value" for a particular territorial unit was developed to simplify and facilitate the practical use of materials from groups of agricultural soils, as well as to determine the financial costs necessary to improve the quality of soil.

\section{References}

1. Babayev M., Hasanov V. (2001) Azərbaycan torpaqlarının müasir təsnifatı və nomenklaturasının nəzəri əsasları (metodiki tövsiyə). (Modern classification of Azerbaijani lands and theoretical bases of the nomenclature (methodical recommendation). Bak1: "Elm", 32 p. (in Azerbaijani).

2. Гаврилюк Ф. (1974) Бонитировка почв. (Soil appraisal). М.: «Высшая школа», 271 p. (in Russian).

3. Мамедов Г. (2000) Земельная реформа в Азербайджане: правовые и научно-экологические вопросы. (Soil reform in Azerbaijan: legal and scientific-environmental issues). Баку: «Элм», 372 p. (in Russian). 
4. Розов Н. (1962) Общий учет и качественная характеристика земельных ресурсов CCCP. (General accounting and qualitative characteristics of land resources of the USSR). В книге.: Проблемы почвоведения. М.: Изд. АН СССР, с. 132-151 (in Russian).

5. Valiyev A. (2011) Torpaq istehsal vasitəsi kimi: əsas müddəalar, nəticələr tövsiyə və təkliflər. (Soil as a means of production: key provisions, results and recommendations). Bakı: "Şərq-Qərb", 84 p. (in Azerbaijani).

Information about authors:

Akif Valiyev, doctor of economic science, associate professor. Agricultural Economics Research Center under the Ministry of Agriculture of Azerbaijan. Baku, Nasimi district, Mir-Calal str., home 37, flat 55, Tel: (+994) 50 624-24-33, akif.valiyev@atm.gov.az Fields of interest: Agriculture, sport, art, nature.

Natig Mirzayev, PhD on economy, associate professor. Lankaran State University. Azerbaijan, Lankaran city, Hazi Aslanov avenue-50, Tel: (+994) 50 664-69-60, mirzoev.n@mail.ru Fields of interest: Development of entrepreneurship in agriculture, efficiency of economic activity of entrepreneurship subjects. 